\title{
Original
}

\section{Effect of Omeprazole Ingestion on Healing of Gastric Ulcers and Serum Gastrin Concentration in Rats}

\author{
Hiroyuki Miki, Hirotaka Yamada, Nozomi Yoshikawa \\ and Keiji Mitamura
}

\begin{abstract}
We induced gastric ulcers in rats by administering a subserosal injection of $20 \%$ acetic acid and assessed the effects of omeprazole (OPZ) and of cimetidine on biosynthesis in the regenerating gastric mucosa and serum gastrin level. Immunohistological study of incorporation of Bromodeoxyuridine (BrdU) into DNA revealed that 3- and 5-day treatments with OPZ caused a significant decrease in the labeling index (LI) in the regenerating mucosa $(38-48 \%$ of control, $p<0.05)$. Seven- and 14-day treatments with omeprazole caused a significant increase in the LI $(170-186 \%$ of control, $p$ $<0.05)$. In contrast, no significant effect was observed in cimetidine-treated rats throughout the entire experimental period. Serum gastrin levels were significantly elevated and reached a maximum $(465 \pm 73 \mathrm{pg} / \mathrm{ml}, 247 \%$ of control, $p<0.05)$ on the seventh day, and remained elevated $(415 \pm 133 \mathrm{pg} / \mathrm{ml}$, $356 \%$ of control, $p<0.05)$ on the fourteenth day in OPZ-treated rats. Such changes were not observed in cimetidine-treated rats. These results suggest that increased serum gastrin, in response to the intragastric neutralization induced by $\mathrm{OPZ}$ administration, could accelerate cellular proliferation in the regenerating mucosa at the ulcer margin.
\end{abstract}

Key words : omeprazole, gastrin, stomach, acetic ulcer

\section{Introduction}

Omeprazole (OPZ), a substituted benzimidazole, suppresses intragastric acid secretion more strongly than $\mathbf{H}_{2}$-receptor antagonists by selectively interfering with the proton pump $\left(\mathrm{H}^{+}, \mathrm{K}^{+}\right.$-ATPase $)$in parietal cells. OPZ has produced excellent results in treating peptic ulcer disease ${ }^{1,2)}$, and has been shown to have other effects on the gastric mucosa in addition to intragastric neutralization ${ }^{3,4)}$. Recently, there has been increasing interest in the effect of OPZ against peptic ulcers accompanied by Helicobacter pylori infection ${ }^{5)}$.

It is widely accepted that sufficient suppression of intragastric acid secretion leads to hypergastrinemia $^{6-8)}$. In a previous report, after 4 weeks of treatment with OPZ, $20 \mathrm{mg} / \mathrm{kg}$ daily, serum gastrin levels rose to $186 \%$ of the pretreatment level in patients with duodenal ulcer $^{9)}$. Gastrin is considered to be an important growth-promoting agent in the gastric mucosa ${ }^{10,11)}$. Evidence that the constant administration of pentagastrin increased the oxyntic mucosal mass was initially presented by Crean et al. ${ }^{12}$ Gastrin also promotes protein

The Second Department of Internal Medicine, Showa University School of Medicine, 1-5-8, Hatanodai, Shinagawa-ku, Tokyo 142-8666, Japan. 
synthesis in the oxyntic mucosa ${ }^{13)}$. The effect of exogenous hypergastrinemia on the rate of cell proliferation was studied in the gastric mucosa of normal humans, and a marked increase in the labeling index ( $\mathrm{LI}$ ) of ${ }^{3} \mathrm{H}$-thymidine was induced by pentagastrin infusion in endoscopic biopsied specimens of the fundic mucosa ${ }^{14}$.

Taken together, gastrin might stimulate epithelial proliferation, even in the regenerating mucosa of an ulcer margin. Therefore, we designed the present study to determine whether the effect of OPZ on ulcer healing, especially in promoting regeneration of mucosa, is influenced by the serum gastrin level. Using an immunohistochemical stain with BrdU, we evaluated DNA synthesis at the regenerating mucosa of acetic acid ulcers of rats, and assessed the changes in the serum gastrin level after administration of OPZ.

\section{Materials and Methods}

\section{Reagents and Antibodies}

OPZ was a generous gift of Yoshitomi Pharmaceuticals (Osaka, Japan). Cimetidine (CMT) was purchased from Fujisawa Pharmaceuticals (Osaka, Japan). Bromo-deoxyuridine (BrdU) and 3,3'-diaminobenzidine tetrahydrochloride were purchased from Sigma (St Louis, MO, USA). All other materials were purchased from Sigma unless otherwise indicated.

Mouse anti-BrdU monoclonal antibody was purchased from Becton Dickinson (San Jose, CA, USA). Peroxidase-conjugated rabbit anti-mouse IgG antibody was purchased from Dakopatts (Glostrup, Denmark). These antibodies were diluted to $1: 50$ in phosphatebuffered saline (PBS) containing $1 \%$ bovine serum albumin for the experiments.

\section{Induction of Gastric Ulcer}

Male Wistar rats seven weeks of age, 180-210 g, were used. Experimental gastric ulcers were induced by the subserosal injection of acetic acid according to Takagi et al. ${ }^{15)}$ In brief, rats were anesthetized with diethyl ether and laparotomized. Then, $0.02 \mathrm{ml}$ of a $20 \%$ solution of acetic acid was injected into the subserosal layer at the fundoantral junction of the gastric anterior wall. After this treatment, the abdominal incisions were sutured and the rats were allowed free access to food and water.

\section{Sample Collection}

The rats were divided into 5 groups as shown in Table 1. In group 1, rats received 20 $\mathrm{mg} / \mathrm{kg}$ bw of OPZ suspended in $2 \mathrm{ml}$ of $0.5 \%$ methyl cellulose with $0.2 \% \mathrm{NaHCO}_{3}$ ( $\mathrm{pH}$ 9 ), once a day by oral intubation. In group 2, rats received the same volume of the vehicle only and served as controls. In group 3, rats received $200 \mathrm{mg} / \mathrm{kg}$ bw of CMT suspended in $2 \mathrm{ml}$ of water, once a day by oral intubation. In group 4, rats received the vehicle only and also served as controls. Administration of substances and vehicles was begun $24 \mathrm{~h}$ after ulcer induction and lasted for 3, 5, 7, or 14 days. Rats in group 5 received no drugs, only water. After being treated for various periods, the rats were deprived of food overnight until the subsequent procedure. Twenty hours after the last dose, $100 \mathrm{mg} / \mathrm{kg}$ bw of BrdU was injected intraperitoneally into each rat to label proliferating cells in the gastric mucosa. One hour later, the rats were sacrificed by cardiac puncture with an $18 \mathrm{GA}$ ( $1.3 \mathrm{~mm}$ diameter) needle and blood was collected for determination of the serum gastrin concentration. Gastrin concentration was determined by $\left[{ }^{125} I\right]$-radio immunoassay with a Gastrin RIA Kit (Dainabot Inc., Osaka, Japan). Then, the stomachs were excised 
Table 1 Summer of the experimental design

\begin{tabular}{|c|c|c|c|}
\hline Group & Subgroup & Treatment & Treatment Period (day) \\
\hline \multirow[t]{4}{*}{ Group 1} & 1 & omeprazole $(20 \mathrm{mg} / \mathrm{kg} \cdot \mathrm{bw})$ & 3 \\
\hline & 2 & omeprazole $(20 \mathrm{mg} / \mathrm{kg} \cdot \mathrm{bw})$ & 5 \\
\hline & 3 & omeprazole $(20 \mathrm{mg} / \mathrm{kg} . b w)$ & 7 \\
\hline & 4 & omeprazole $(20 \mathrm{mg} / \mathrm{kg} . \mathrm{bw})$ & 14 \\
\hline \multirow[t]{4}{*}{ Group 2} & 1 & Vehicle & 3 \\
\hline & 2 & Vehicle & 5 \\
\hline & 3 & Vehicle & 7 \\
\hline & 4 & Vehicle & 14 \\
\hline \multirow[t]{4}{*}{ Group 3} & 1 & cimetidine $(200 \mathrm{mg} / \mathrm{kg} \cdot \mathrm{bw})$ & 3 \\
\hline & 2 & cimetidine $(200 \mathrm{mg} / \mathrm{kg} \cdot \mathrm{bw})$ & 5 \\
\hline & 3 & cimetidine $(200 \mathrm{mg} / \mathrm{kg} . \mathrm{bw})$ & 7 \\
\hline & 4 & cimetidine $(200 \mathrm{mg} / \mathrm{kg} . \mathrm{bw})$ & 14 \\
\hline \multirow[t]{4}{*}{ Group 4} & 1 & Vehicle & 3 \\
\hline & 2 & Vehicle & 5 \\
\hline & 3 & Vehicle & 7 \\
\hline & 4 & Vehicle & 14 \\
\hline
\end{tabular}

Group 1 rats received $20 \mathrm{mg} / \mathrm{kg}$ oneprazole in $2 \mathrm{ml}$ of $0.5 \%$ methyl cellulose with $0.2 \% \mathrm{NaHO}_{3}$. Group 2 rats received $2 \mathrm{ml}$ of vehicle $(0.5 \%$ methyl cellulose with $\left.0.2 \% \mathrm{NaHO}_{3}\right)$. Group 3 rats received $200 \mathrm{mg} / \mathrm{kg}$ cimetidine in $2 \mathrm{ml}$ of water. Group 4 rats received $2 \mathrm{ml}$ of vehicle (water) only. Each subgroup was composed of three to six rats.

immediately and opened along the greater curvature. After rinsing in saline, the stomachs were stretched on boards mucosal side up, and the ulcer indices (UI), which were determined by the length and the width of the ulcers, were determined. Then the stomachs on the boards were fixed in $70 \%$ ethanol for 24 hours at $4^{\circ} \mathrm{C}$. Specimens of mucosa at the ulcer margin were cut and processed for immunohistochemical detection of BrdU and routine histological study by staining with haematoxylin and eosin.

\section{Immunohistochemical Study}

Immunohistochemical staining with anti-BrdU antibody was performed by the indirect immunoperoxidase method as follows: For each sample, two $4-\mu \mathrm{m}$ sections of fixed, paraffin-embedded tissues were stained according to the method reported by Tada et al. ${ }^{16)}$ One additional section was stained with hematoxylin and eosin for routine histological study. For BrdU staining, sections were deparaffinated, rehydrated and incubated in a solution of $0.3 \%$ hydrogen peroxide in $100 \%$ methanol for 30 minutes to block endogenous peroxide activity. Then the sections were washed in PBS and incubated in $2 \mathrm{~N} \mathrm{HCl}$ for 1 hour to partially denature the DNA in the sections to obtain single-stranded regions of DNA. After another wash in PBS, the sections were incubated with mouse-anti BrdU monoclonal antibody for 1 hour at room temperature. After another wash with PBS, they were incubated with peroxidase conjugated-rabbit-anti-mouse IgG antibody for $30 \mathrm{~min}$ at room temperature. After additional washes, bound peroxidase was developed with 3, 3'diaminobenzidine-tetrahydrochloride for $15 \mathrm{~min}$. Subsequently, sections were counterstained with Mayer's haematoxylin, dehydrated, and mounted. 


\section{Cell Counting}

Immunohistologically stained cells were viewed under a microscope (Olympus BH-2, Olympus, Tokyo, Japan). The microscopic images $(\times 100)$ of the ulcer margins were photographed with a camera (Olympus C-35AD-4, Olympus, Tokyo, Japan) mounted on the microscope. We scanned these photographs with a flatbed image-scanner (Epson GT-8000, Seiko Epson Inc., Tokyo, Japan) and transferred them to the Macintosh computer using image-processing software (Adobe Photoshop 2.5J, Adobe Systems Inc., USA). Then we analyzed the transferred pictures utilizing image-analysis software (Image 1.55, NIH, USA). This procedure allowed us to obtain high resolution of the structures of the sections and to perform quantitative image analysis. Using the density slicing program, the BrdU-labeled cells were highlighted in red and backgrounds were left unchanged. These procedures were performed under the same conditions and settings through the entire experiment. According to Helpap et al. ${ }^{17)}$, we determined the proliferating zone as the area between uppermost and lowermost BrdU-labeled cells. The proliferative zone gradually increased in width as it got closer to the ulcer edge, and formed a wedge-shaped regenerating area where BrdU-positive cells had been densely distributed. After determining the regenerating area, we traced along the boundary of the area, and square measure of each area was obtained by the imageanalyzing software. Subsequently, highlighted BrdU-labeled cells in thresholded images were automatically counted. The density of BrdU-labeled cells was calculated by dividing the number of counted cells by the square measure of the area, and expressed as BrdU-LI.

\section{Statistical Analysis}

Data were expressed as mean \pm SD. Student's $t$ test was used to evaluate the significance of differences. A probability of $p$ less than 0.05 was taken as the level of significance. All analyses were performed utilizing the Stat View statistical software (Ver. 4.0, Abacus Concepts Inc., Berkeley, CA).

\section{Results}

\section{General Comments}

All treatments were well tolerated and no adverse effects were noted in any rats during the experimental period.

\section{Ulcer Index}

The time course of the UI is shown in Figure 1. On the third, fifth, and seventh day of the treatment, the UI of rats treated with either OPZ or CMT was a little lower than that of controls. However, there was no significant difference between the UI of each treated rat and that of the corresponding controls throughout the experimental period.

\section{BrdU-Labeling Index}

Proliferating, S-phase cells were positively stained in the ulcer margin (Fig. 2A), at the site of regenerating mucosa. A representative processed image is shown in Figure $2 B$ and 2C (third day of OPZ treatment). In control rats for OPZ treatment, the LI reached a maximum on day $3\left(11.17 \pm 4.9 \times 10^{2} / \mathrm{mm}^{2}\right)$, then decreased gradually (Fig. 3A). In the OPZ-treated rats, while 3-and 5-day treatments significantly decreased LI ( $52 \%$ of control, day $3 ; 62 \%$ of control, day 5), 7- and 14-day treatments significantly increased LI (186\% 
B
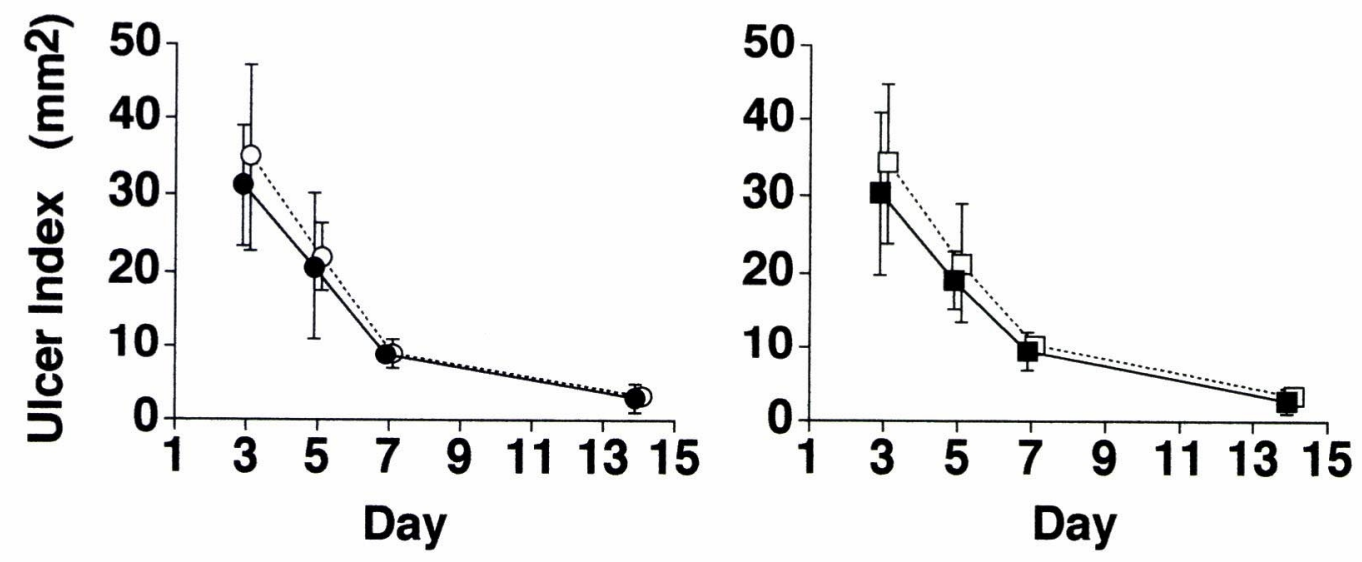

Fig. 1. Time course of ulcer index (UI) in OPZ-treated rats (A) and CMT-treated rats (B) compared to the corresponding controls. The symbols used in the figure are : OPZ-treated rats; $\bigcirc$, Controls of OPZ-treated rats ; $\mathbf{\square}$, CMT-treated rats; $\square$, Controls of CMT-treated rats. Points and bars are means $\pm S D$ of three to five rats.
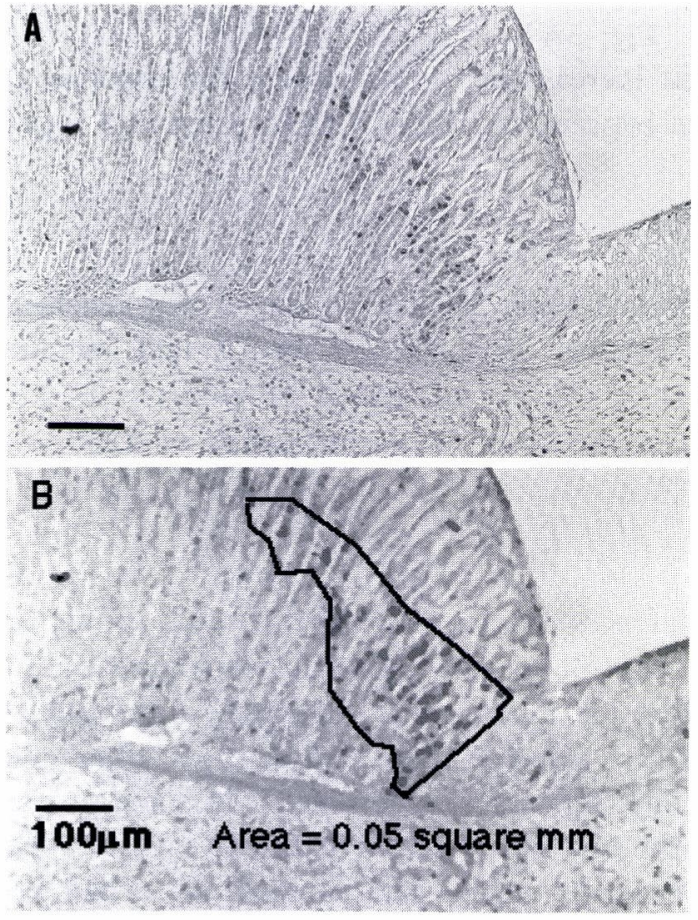

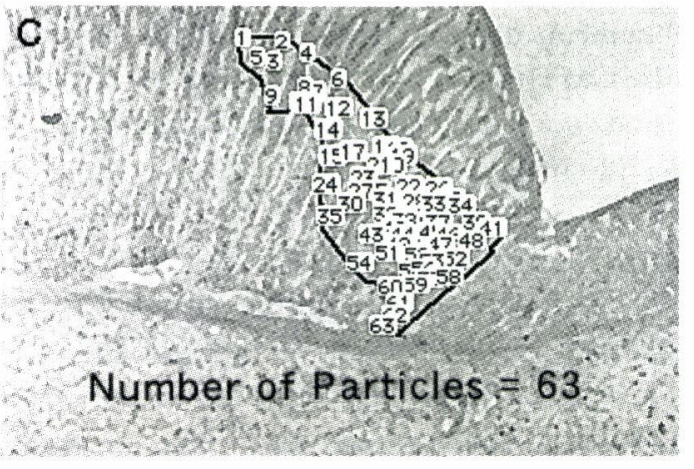

Fig. 2. Gastric mucosa of the ulcer margin on the third day of the treatment with OPZ, stained by indirect immunoperoxidase method with anti-BrdU antibody, showing the distribution of BrdU-labeled cells in the regenerative mucosa. A: Representative microscopic image of BrdU-staining. Original magnification, $\times 100$. Scale bar represents $100 \mu \mathrm{m}$. B : Processed image of the microscopic picture using image-analyzing software (NIH image 1.55). The area traced by the line is proliferative zone at the ulcer margin. C : Image of analyzed image by $\mathrm{NIH}$ image 1.55 , demonstrating the number of BrdUlabeled cells in the proliferative area. 

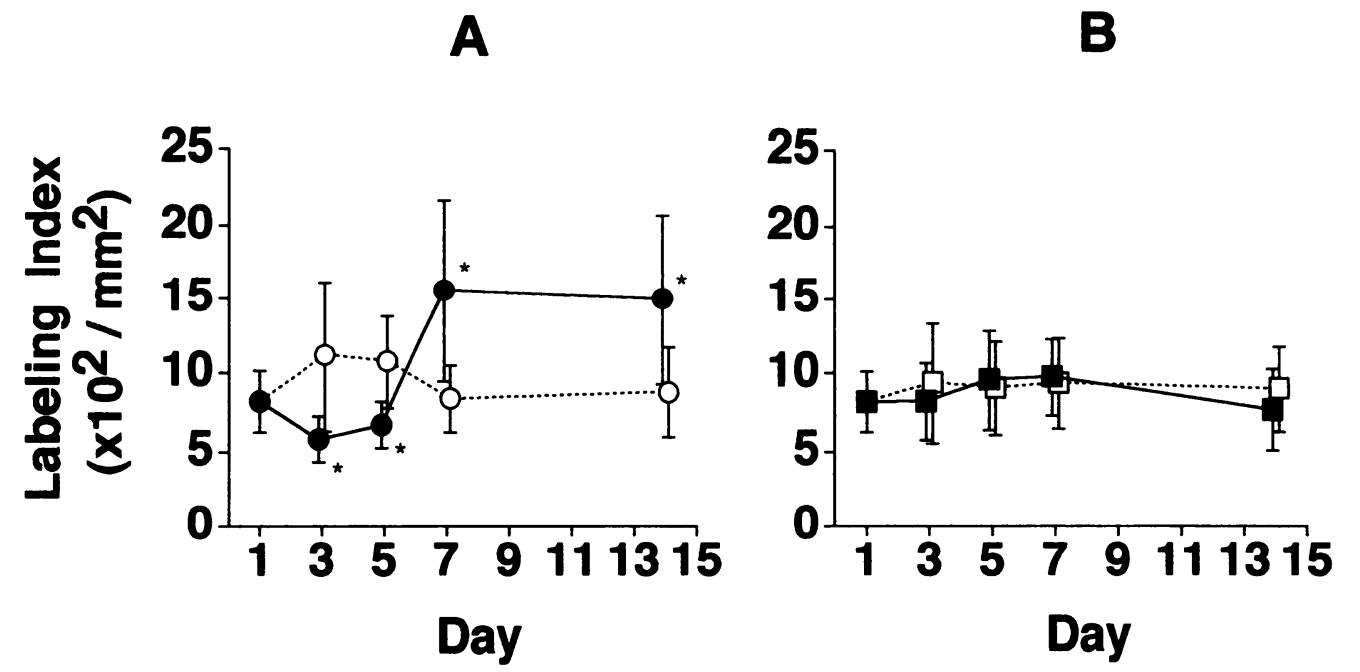

Fig. 3. Time course of labeling index (LI) of OPZ-treated rats (A) and CMT-treated rats (B) compared to that of the corresponding controls.

The symbols used in the figure are: $\bigcirc$, OPZ-treated rats; $\bigcirc$, Controls of OPZ-treated rats ;

$\square$, CMT-treated rats ; $\square$, Controls of CMT-treated rats.

Points and bars are means $\pm \mathrm{SD}$ of four to five rats. ${ }^{*}: p<0.05$ vs control.

of control, day $7 ; 170 \%$ of control, day 14) (Fig. 3A).

In CMT-treated rats, there was no significant increase in LI throughout the experimental period, nor was there any significant difference between the LI of CMT-treated and control rats (Fig. 3B).

\section{Serum Gastrin Concentration}

In OPZ-treated rats, serum gastrin concentrations were elevated on day 5 and reached a maximum value $(465 \pm 73 \mathrm{pg} / \mathrm{ml}, 247 \%$ of control, $p<0.05)$ on day 7 and remained significantly higher on the fourteenth day $(415 \pm 133 \mathrm{pg} / \mathrm{ml}, 356 \%$ of control, $p<0.05)$ (Fig. 4A). In contrast, there was no significant difference in serum gastrin concentration between rats treated with CMT and controls (Fig. 4B).

\section{Histological Study}

There were no significant histological differences among the OPZ-treated group, the CMT-treated group and their respective vehicle control groups. General histological findings were as follows. One day after ulcer production, the mucosa was completely destroyed and only necrotic or charred tissue remained in the injured area. Three days after ulcer production, a slight inward rolling of the marginal mucosa was observed. In some sections, a thin layer of epithelial surface-cells had grown over the denuded connective tissue. Five days after ulcer production, the injured area appeared about half as wide as it had been earlier. No significant changes in the regenerative zone were observed as compared to day 3. Seven days after ulcer production, the defect in the mucosa had become smaller and most of the epithelial formations along this area seemed to have fully regenerated. At this stage and later, many buds, composed of mucous neck cells, appeared at the base and sides 

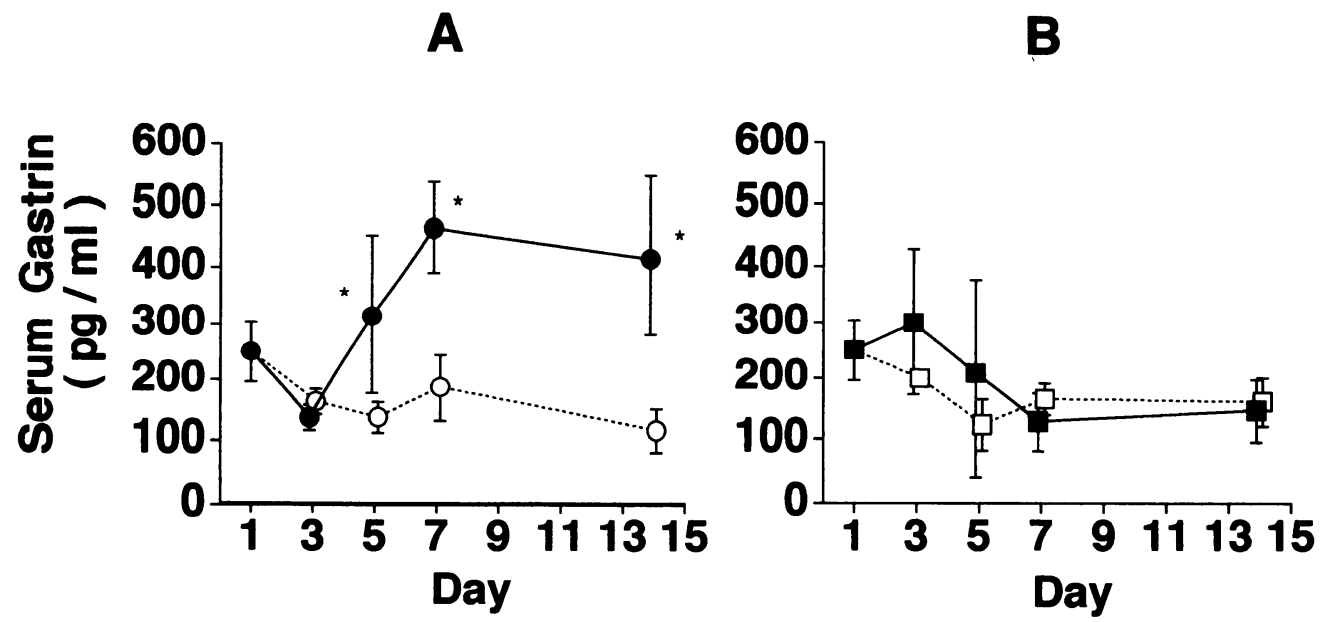

Fig. 4. Time course of serum gastrin concentration of OPZ-treated rats (A) and CMT-treated rats (B) compared to the corresponding controls.

The symbols used in the figure are: $O$, OPZ-treated rats; $\bigcirc$, Controls of OPZ-treated rats ;

$\square$, CMT-treated rats; $\square$, Controls of CMT-treated rats.

Points and bars are means $\pm \mathrm{SD}$ of three to four rats. ${ }^{*}: p<0.05$ vs control.

of the regenerated mucosa, giving the appearance of branched glands. Fourteen days after ulcer production, the wounds were covered with regenerating mucosa in most cases. A thin layer of cells had bridged the gap in several sections.

\section{Discussion}

The present study showed that treatment with OPZ for at least 7 days increased the serum gastrin concentration and enhanced the rate of cellular proliferation in the regenerating mucosa. Various factors regulate gastric ulcer healing, such as cellular proliferation, microcirculation of gastric mucosa, mucus production, intragastric acidity and vascularization of regenerating mucosa. Above all, evaluation of cellular proliferation in the regenerating mucosa is one of the useful methods for assessing ulcer healing. Former investigators have used methods such as measuring incorporation of ${ }^{3} \mathrm{H}$-thymidine by autoradiography ${ }^{4,18,19)}$ or BrdU with immunohistochemical staining ${ }^{20,21)}$ to determine S-phase cell kinetics in the gastric mucosa. The combination technique of labeling with BrdU and indirect immunoperoxidase staining has been widely used in studying cellular proliferation and kinetics in the gastric mucosa. In the most commonly used method, LI was determined by the following steps. By use of a grid, BrdU-positive cells and background mucosal cells were counted in microscopic fields.

The percentage of labeled cells to the total number of background epithelial cells was then calculated as LI. However, this method has some problems. In the intact gastric mucosa, the proliferating zone is commonly defined as the region between the uppermost parietal cells and the uppermost zymogen cells ${ }^{22}$. At the ulcer margin, the distribution of BrdU-labeled cells was quite different from that in the intact gastric mucosa. The labeled cells were distributed much wider, more focally, and more unequally as compared to the intact mucosa. If the ulcer margin was examined by the common method described above, 
the result would be greatly influenced by the microscopic field chosen for counting cells. Therefore, in the present study, we determined the proliferating zone as the area between uppermost and lowermost labeled cells at the ulcer margin, where BrdU-positive cells were focally and densely distributed. Then, we utilized image analyzing software to trace and measure the regenerating area, and counted the labeled cells inside the area. This method has several advantages. First, since the cells are counted by computer, it is much quicker. Second, we can avoid bias when we determine BrdU-positive cells, since the computer program automatically defines the labeled cells.

The LI at the proliferating zone in the regenerating mucosa increased significantly on the seventh day of treatment with OPZ and remained elevated on day 14 . These results suggest that OPZ-administration may promote cellular proliferation in the regenerating mucosa, and sustain such promotion even at the late stage of ulcer formaiton. Unexpectedly, the LI of OPZ-treated rats on the third and fifth day of the treatment was rather low compared to controls. We can not properly explain this finding, but suggest that it may be linked to some unknown effect of OPZ at the early stage of ulcer healing. Furthermore, since the gastric mucosa at the acute stage of acetic ulcer is extremely injured and inflamed, intragastric neutralization induced by OPZ may have some unknown influence upon gastric mucosa. Further investigation is required to explain this finding.

Despite the marked change in LI, there was no significant difference in the histological structure of ulcers between OPZ-treated rats and controls. An increase in cellular proliferation observed in the present study may be insufficient to induce histological change. We presume that an increase in cellular proliferation maintained for sufficiently long period will produce a detectable effect on the histological structure.

In the present study, treatment with OPZ elevated serum gastrin levels which reached a maximum on day 7 and remained elevated until the end of the treatment. These results are consistent with a number of previous reports regarding the effect of OPZ on serum gastrin level. Walsh reported that the oral administration of OPZ to rats induced hypergastrine$\mathrm{mia}^{10)}$. Li and Helander reported that plasma gastrin level was 5- to 6-fold elevated by OPZ administration ${ }^{4)}$. In the present study, on the third day of treatment with OPZ, the serum gastrin level was not significantly different from that of controls. This result suggests that the suppressive effect of OPZ on intragastric acidity might not be optimal by the third day. Lind et al studied the relationship between reduction of gastric acid secretion and serum gastrin concentration during the administration of OPZ, and reported that at least 5 days of treatment was required to establish the stable suppression of acid secretion ${ }^{6)}$. However, in both OPZ-treated and CMT-treated rats, the serum gastrin concentration decreased from the first to the third day, indicating that the conditions of gastrin secretion in the early phase of the experimental period (until the fifth day) differed from those in the late phase (days 7-14). Various factors such as the stress of laparotomy, the anesthesia and host defense against acute mucosal injury may influence gastrin secretion in the early phase and make it more complicated than in the late phase.

Administration of CMT did not affect.LI through the entire experimental period. This result is supported by previous reports ${ }^{23,24)}$. There was no significant difference in serum gastrin level between CMT-treated rats and controls. Seima et al. reported that serum gastrin concentration increased when CMT was administered intraperitoneally to rats ${ }^{25)}$. A study of patients with peptic ulcers showed that treatment with CMT increased serum 
gastrin levels ${ }^{26)}$. The methodological difference, such as the mode of drug administration, may explain our findings that CMT-treatment did not affect serum gastrin level. It is possible that the dosage of CMT we used is insufficient to inhibit acid secretion in rats.

A number of studies have examined the trophic effect of gastrin on the oxyntic mucosa. Most studies confirmed that either an increase in endogenous gastrin or exogenously administered gastrin stimulated cellular growth in the gastric mucosa. Administration of pentagastrin to rats led to a significant increase in incorporation of ${ }^{3} \mathrm{H}$-thymidine in the oxyntic gland area ${ }^{27)}$. Other studies confirmed that endogenous hypergastrinemia induced by surgical manipulation produced trophic effects in the oxyntic mucosa that paralleled changes in circulating gastrin ${ }^{11,26)}$.

In conclusion, we have demonstrated that endogenous hypergastrinemia induced by the administration of OPZ increased the cellular proliferation in the ulcer margin that might accelerate the ulcer healing process. This observation might indicate an additional effect of OPZ in ulcer healing other than intragastric neutralization.

\section{References}

1) McFarland RJ, Bateson MC, Green JRB, O'Donoghue DP, Dronfield MW, Keeling PW, Burke GJ, Dickinson RJ, Shreeve DR, Peers EM and Richardson PDI : Omeprazole provides quicker symptom relief and duodenal ulcer healing than ranitidine. Gastroenterology, $98: 278-283$ (1990)

2) Massimo Claar G, Monaco S, Del Veccho Blanco C, Capurso L, Fusillo $M$ and Annibale B : Omeprazole 20 or $40 \mathrm{mg}$ daily for healing gastroduodenal ulcers in patients receiving non-steroidal anti-inflammatory drugs. Aliment Pharmacol Ther, 12 : 463-468 (1988)

3) Schmassmann A, Tarnawski A, Peskar BM, Varga L, Frogerzi B and Halter F: Influence of acid and angiogenesis on kinetics of gastric ulcer healing in rats: interaction with indomethacin. Am J Physiol, 268 : G276-G285 (1995)

4) $\mathrm{Li} \mathrm{H}$ and Helander HF : Hypergastrinemia increases proliferation of gastroduodenal epithelium during gastric ulcer healing in rats. Dig Dis Sci, $41: 40-48$ (1996)

5) Bianchi Porro G, Parente F, Imbesi V, Montrone F and Caruso I : Role of Helicobacter pylori in ulcer healing and recurrence of gastric and duodenal ulcers in long-term NSAID users. Response to omeprazole dual therapy. Gut, 39 : 22-26 (1996)

6) Lind $T$, Cederberg $C$, Forssell $\mathrm{H}$, Olausson $M$ and Olbe $\mathrm{L}$ : Relationship between reduction of gstric acid secretion and plasma gastrin concentration during omeprazole treatment. Gastroenterology, 23 : 1259-1266 (1988)

7) Waldum HL, Lehy T, Brenna E, Sandvik AK, Petersen H, Sognen BS, Bonfils S and Lewin MJ : Effect of the histamine-1 antagonist astemizole alone or with omeprazole on rat gastric mucosa. Scand $J$ Gastroenterol, 26 : 23-35 (1991)

8) Simoens C, Woussen-Colle MC and Graff JD : Effect of acute suppression of acid secretion by omeprazole on postprandial gastrin release in conscious dogs. Gastroenterology, $97: 837-845$ (1989)

9) Lind $T$, Oederberg $C$, Olausson $M$ and Olbe $L$ : 24-hour intragastric acidity and plasma gastrin after omeprazole treatment and after proximal gastric vagotomy in duodenal ulcer patient. Gastroenterology, 99 : 1593-1598 (1990)

10) Walsh JH : Role of gastrin as a trophic hormone. Digestion, 47(Suppl 1): 1-16 (1990)

11) Hakanson R and Sundler F : Trophic effects of gastrin. Scand J Gastroenterol, 26(Suppl 180) : 130-136 (1991)

12) Crean GP, Marshall MW and Rumsey RD : Parietal cell hyperplasia induced by administration of pentagastrin (ICI50, 123) to rats. Gastroenterology, $57: 147-155$ (1969)

13) Johnson LR, Aures D and Yuen L : Pentagastrin-induced stimulation of protein synthesis in the gastrointestinal tract. Am J Physiol, 217 : 251-254 (1969)

14) Hansen $\mathrm{OH}$, Pedersen T, Larsen JK and Rehfeld JF : Effect of gastrin on gastric mucosal cell proliferation in man. Gut, $17: 536-541$ (1976)

15) Takagi K, Okabe S and Saziki R : A new method for the production of chronic gastric ulcer in rats and the effect of several drugs on its healing. Jpn J Pharmacol, $19: 418-426$ (1969)

16) Tada T, Kodama $T$, Watanabe $S$, Sato $Y$ and Shimosato $Y$ : Immunohistochemical cell kinetic study of human lung cancer by using monoclonal antibody to bromodeoxyuridine. Jpn J Clin Oncol, 16 : 129-135 (1986) 
17) Helpap B, Hattori T and Gedigk P : Repair of gastric ulcer. A cell kinetic study. Virchows Arch Pathol Anat, 392 : 159-170 (1981)

18) Messier R: Radioautographic evidence for the renewal of the mucous cells in the gastric mucosa of the rat. Anat Rec, $36: 242-253$ (1960)

19) Willems $G$ and Lehy $T$ : Radiographic and quantitative studies on parietal and peptic cell kinetics in the mouse. Gastroenterology, $69: 416-426$ (1975)

20) Biasco G, Paganelli GM, Miglioli M and Barbara L: Cell proliferation biomarkers in the gastrointestinal tract. J Cell Biochem Suppl, 16G : 73-78 (1992)

21) Patel S, Rew DA, Taylor I, Potten CS, Owen C and Roberts SA : Study of the proliferation in human gastric mucosa after in vivo bromodeoxyuridine labelling. Gut, $34: 893-896$ (1993)

22) Tielmans Y, Hakanson R, Sundler F and Willems G: Proliferation of enterochromaffin-like cells in omeprazole-treated hypergastrinemic rats. Gastroenterology, $96: 723-729$ (1989)

23) Okuhira M, Nakano T, Kitajima T, Maruoka M, Hiramatsu A, Mizuno $T$ and Inoue $K$ : Cell proliferation kinetics in the marginal mucosa of gastric ulcer evaluated by immunostaining of DNA polymerase alpha. Digestion, 48 : 185-191 (1991)

24) Eastwood GL and Quimby GF: Effect on chronic cimetidine ingestion on fundic and antral epitherial proliferation in the rat. Dig Dis Sci, 28 : 61-64 (1983)

25) Seima $Y$ and Itoh $T$ : Effect of cimetidine on deoxyribonucleic acid biosynthesis in gastrointestinal mucosa of rats. Jpn J Pharmacol, 31 : 269-274 (1981)

26) Tielemans Y, Axelson J, Sundler F, Willems G and Hakanson R: Serum gastrin concentration affects the self replication rate of the enterochromaffin-like cells in the rat stomach. Gut, 31 : 274-278 (1990)

27) Solomon TE : Trophic effects of pentagastrin on gastrointestinal tract in fed and fasted rats. Gastroenterology, 91 : 108-116 (1986)

[Received February 9, 1999 : Accepted February 16, 1999] 